\title{
LEUKOKINETIC STUDIES. III. THE DISTRIBUTION OF GRANULOCYTES IN THE BLOOD OF NORMAL SUBJECTS *
}

\author{
By J. W. ATHENS, S. O. RAAB, O. P. HAAB, † A. M. MAUER, H. ASHENBRUCKER, \\ G. E. CARTWRIGHT AND M. M. WINTROBE \\ (From the Department of Medicine, Unizersity of Utah College of Medicine, \\ Salt Lake City, Utah)
}

(Submitted for publication August 15, 1960; accepted September 14, 1960)

In a previous publication (1) it was noted that when granulocytes were labeled in vitro with radioactive diisopropylfluorophosphate $\left(\mathrm{DFP}^{32}\right)$ and then returned to the circulation of the donor, about half of the labeled cells could not be found in the circulation at the completion of the infusion $\left(\mathrm{T}_{0}\right)$. Thereafter the remaining labeled cells left the circulation in a random fashion with a mean halftime disappearance $\left(\mathrm{T}_{\frac{1}{2}}\right)$ of 6.6 hours.

Since cell damage and significant elution of the label could not be demonstrated under the conditions of the study, it was suggested that the immediate disappearance of half the infused cells was due to their rapid dilution in a larger pool than that calculated from the blood volume and the venous granulocyte count.

The concept that the circulating granulocyte pool (CGP) does not constitute all of the intravascular leukocytes is not new. Vejlens (2) reviewed the numerous investigations carried out up to 1938 and pointed out that as early as 1867 Cohnheim observed white cells in a marginal position along the walls of venules. By microscopic examination it has since been demonstrated that leukocytes may circulate freely in the blood, adhere to the vascular endothelium in sites where the blood flow is relatively slow and then once again re-enter the circulation in a process of continuous exchange (2).

If $\mathrm{DFP}^{32}$-labeled granulocytes come into rapid equilibrium with marginated granulocytes, it might be expected that one could account for most if not all of the labeled cells by mobilizing the marginated cells into the circulation with epinephrine. Mo-

* This investigation was supported in part by research grants (C-2231 and CY 2349) from the National Cancer Institute and in part by a graduate training grant (2A5098) from the National Institute of Arthritis and Metabolic Diseases, Bethesda, Md.

$\dagger$ Fellow of the Leukemia Society Inc., New York, N. Y. bilization of the marginated cells into the circulation after equilibration has occurred should not alter the specific activity of the cells in the CGP.

The purpose of this paper is to present evidence that labeled granulocytes are distributed in a larger pool than the CGP and to present data on the size of this distribution compartment in 45 normal subjects.

\section{MATERIAL AND METHODS}

Volunteers from the Ltah State Prison were used in these studies. All of the subjects were healthy cooperative males, 20 to 50 years of age, with normal leukocyte values, who were free of even minor infections. The subjects were allowed to have breakfast at 6 a.m. The infusion of labeled blood was begun between 8 and 10 a.m.

The methods for labeling granulocytes in vitro (1), for the isolation of leukocytes from the blood samples and for the determination of leukocyte radioactivity were described previously (3).

Total and differential leukocyte counts were made at the beginning of an experiment and at appropriate time intervals during the study. When reference is made in the text to granulocyte pools, these terms refer to the neutrophilic granulocyte series. Eosinophils and basophils have not been included in the granulocyte total because, by means of autoradiographic studies with tritiated DFP, it has been found that these cells do not label (4).

The number of granulocytes per millimeter cubed was calculated from the total and the differential leukocyte counts. The blood volume of a subject was assumed to be $2.68 \mathrm{~L}$ per $\mathrm{m}^{2}$ of body surface area (5). The surface area was estimated from the nomogram of $\mathrm{Du}$ Bois (6). The circulating granulocyte pool was calculated from the number of granulocytes per millimeter cubed and the estimated blood volume.

Three $20 \mathrm{ml}$ samples of blood were removed from the bag just prior to the infusion, and the specific activity of the isolated leukocytes, expressed as counts per minute per milligram of leukocyte nitrogen, was determined. The mean value for the 3 determinations was taken to represent the specific activity of the granulocytes in the hag ( $\mathrm{SA}$ of bag $\mathrm{G}$ ). The concentration of granulocytes in the bag was calculated from the total and differential leukocyte counts determined directly on the bag blood after incubation with $\mathrm{DFP}^{32}$. The volume of blood ad- 
ministered to the subject, usually between 450 and $500 \mathrm{ml}$, was calculated from the weight of blood injected and an assumed specific gravity of 1.055 . The total number of labeled granulocytes given to the subject (no. G in bag) was then calculated.

The blood was administered to the original donor over a 15 to 20 minute period. Within 3 minutes after the completion of the infusion $\left(\mathrm{T}_{0}\right)$, three $20 \mathrm{ml}$ samples of blood were withdrawn from the subject and the specific activity of the granulocytes in the circulation was determined. The mean value of the 3 determinations was taken to represent the specific activity of the granulocytes in the blood at $\mathrm{T}_{0}$ (SA blood $\mathrm{G}$ ).

The percentage of infused cells present in the CGP at $\mathrm{T}_{0}$ was calculated as follows:

Per cent of infused G present in CGP at $\mathrm{T}_{0}$

$$
=\frac{\text { CGP } \times \text { SA blood G }}{\text { no. G in bag } \times \text { SA of bag G }} \times 100 .
$$

The number of cells in the total blood granulocyte pool (TBGP) was calculated as follows:

$$
\text { TBGP }=\frac{\text { SA of bag } G \times \text { no. } G \text { in bag }}{\text { SA of blood } G} .
$$

\section{RESULTS}

Influence of epinephrine and exercise on the percentage of infused granulocytes present in the circulation at $T_{0}$. In an attempt to account for the labeled cells apparently lost from the circulation during the infusion, the following studies were carried out. Blood from each of five subjects was labeled with $\mathrm{DFP}^{32}$, infused into the donor, and the percentage of infused graulocytes present in the circulation at $T_{0}$ determined. Five days later the studies were repeated in the same subjects except that $0.5 \mathrm{mg}$ of epinephrine was added to the labeled blood just prior to infusion. In each epinephrine study, as compared with the control, there was an increase in granulocyte count at the end of the infusion ranging from 37 to 179 per cent. In addition, the percentage of infused granulocytes in the circulation increased from a mean of 48.0 to a mean of 78.8. Nevertheless, in no instance could all of the infused cells be accounted for in the circulation (Table I).

Similar studies were carried out in four additional subjects except that a 440 yard run at the completion of the infusion was used to mobilize granulocytes rather than epinephrine. After exercise the granulocyte count increased 64 per cent on the average and the proportion of infused granulocytes which could be accounted for in the cir-
TABLE I

Influence of epinephrine on the percentage of infused granulocytes present in the CGP at $T_{0}{ }^{*}$

\begin{tabular}{llcl}
\hline \multicolumn{4}{c}{$\begin{array}{c}\text { Per cent infused } \\
\text { in CGP at } T_{0}\end{array}$} \\
\cline { 2 - 4 } Subject & Control & Ejpinephrine & $\Delta \mathrm{G} \dagger$ \\
\hline II-164 & 47 & 88 & 1.72 \\
II-166 & 55 & 82 & 1.37 \\
II-168 & 52 & 81 & 1.42 \\
II-204 & 49 & 71 & 1.99 \\
II-208 & 37 & 72 & 2.79 \\
Mean & 48.0 & 78.8 & 1.86
\end{tabular}

$* \mathrm{G}=$ granulocytes $; \mathrm{CGP}=$ circulating granulocyte pool; $\mathrm{T}_{0}=$ completion of infusion.

$\dagger$ Ratio of granulocyte count at $T_{0}$ of epinephrine study to that in the control study.

culation increased from an average of 45 to 79 per cent. The results varied considerably. It is of interest that in two subjects (III-4 and III-10) 96 and 100 per cent of the infused cells were found in the circulation (Table II).

Influence of epinephrine and of exercise on the specific activity of the granulocytes in the circulation. To assess the possibility of a continual exchange of granulocytes between the CGP and the marginated cells, each of eight subjects was given an infusion of autogenous, DFP ${ }^{32}$-labeled blood. Three hours after completion of the infusion, at which time the granulocyte disappearance curve was well established, the concentration and the specific activity of the granulocytes in the CGP were determined. Immediately thereafter $0.4 \mathrm{mg}$ epinephrine in $50 \mathrm{ml}$ of isotonic saline was administered intravenously over a period of 4 to 27 minutes. The concentration and the specific activity of the granulocytes were measured again. In two subjects the granulocyte count increased

TABLE II

Influence of exercise on the percentage of infused granulocytes present in the $C G P$ at $T_{0}$

\begin{tabular}{llrl}
\hline & \multicolumn{2}{c}{$\begin{array}{c}\text { Per cent infused } \\
\text { in CGP at } \text { T }_{0}\end{array}$} \\
\cline { 2 - 3 } Subject & Control & Exercise & $\Delta \mathrm{G}^{*}$ \\
\hline III-2 & 30 & 54 & 1.73 \\
III-4 & 43 & 101 & 2.38 \\
III-10 & 62 & 96 & 1.25 \\
III-12 & 55 & 65 & 1.18 \\
Mean & 45.0 & 79.0 & 1.64
\end{tabular}

* Ratio of granulocyte count at $T_{0}$ of exercise study to that in the control study. 
TABLE III

The effect of epinephrine and exercise on granulocyte specific activity $(S A)$ *

\begin{tabular}{lrrr}
\hline & \multicolumn{2}{c}{ SA, cpm per mg N } & \\
\cline { 2 - 3 } & Before & After & $\Delta \mathrm{G} \dagger$ \\
\hline Epinephrine infusion $\ddagger$ & 1,387 & 1,331 & 1.47 \\
Exercise (440 yard run) & 697 & 756 & 1.23 \\
\hline
\end{tabular}

* The epinephrine or exercise was administered 3 hours after infusion of the labeled blood.

$\dagger$ Ratio of granulocyte count after epinephrine injection or exercise to that before.

$¥$ Values are the mean of 6 subjects.

$\S$ Values are the mean of 2 subjects.

less than 10 per cent and these studies were, therefore, discarded. In the other six subjects, the mean granulocyte count increased 47 per cent and yet there was no significant change in the specific activity of the granulocytes in the CGP (Table III).

A similar study was carried out in three subjects except that a 440 yard run was used in place of epinephrine. Neutrophilia was not observed in one subject. Therefore, this subject is not included in Table III. The mean granulocyte count in the other two subjects increased 23 per cent in about 2 minutes with no significant change in the specific activity of the granulocytes in the CGP.

Inability of epinephrine to mobilize damaged granulocytes. To determine whether cells which have been deliberately damaged and presumably have been rapidly removed from the CGP could be mobilized back into the CGP by an infusion of epinephrine, blood was withdrawn from four subjects, labeled with $\mathrm{DFP}^{32}$ and stored for 24 hours at $4^{\circ} \mathrm{C}$. Storage of blood has previously been shown to result in the immediate disappearance from the CGP of over 90 per cent of the injected

TABLE IV

Failure of epinephrine to mobilize damaged granulocytes

\begin{tabular}{ccc}
\hline & \multicolumn{2}{c}{$\begin{array}{c}\text { Per cent of infused } \mathrm{G} \\
\text { present in CGP at } \mathrm{T}_{0}\end{array}$} \\
\cline { 2 - 3 } Subject & Stored cells & $\begin{array}{r}\text { Stored cells } \\
+ \\
\text { epinephrine }\end{array}$ \\
\hline I-119 & 9.3 & 9.9 \\
I-121 & 5.3 & 5.9 \\
I-153 & 8.0 & 6.8 \\
I-155 & 3.9 & 5.4 \\
Mean & 6.6 & 7.0 \\
\hline
\end{tabular}

cells (1). The cells were then infused into the respective donors and the fraction of the injected cells present in the circulation at $\mathrm{T}_{0}$ was determined. No untoward reactions occurred during or after the infusions and the granulocyte counts remained unchanged.

The studies were repeated in the same individuals at a later date, and $0.4 \mathrm{mg}$ of epinephrine was added to the blood in the bag. The results are presented in Table IV. The damaged granulocytes were rapidly removed from the circulation during the infusion and were not in the circulation at $T_{0}$. Furthermore, the epinephrine failed to mobilize the damaged cells even though a mean increase in granulocyte count of 23 per cent occurred.

The size of the TBGP and CGP in 45 normal subjects. Since the apparent loss of 50 per cent of the $\mathrm{DFP}^{32}$-labeled granulocytes during the infusion appears to be due to their distribution in a pool larger than the CGP and not due to cell damage, the size of this distribution compartment (TBGP) was measured in 45 normal subjects (Table V).

The mean TBGP was $65.3 \times 10^{7}$ granulocytes per $\mathrm{kg}$ of body weight and the mean CGP was $30.7 \times 10^{7}$ granulocytes per $\mathrm{kg}$.

Influence of epinephrine and of exercise on the distribution of granulocytes within TBGP. To ascertain the effect of epinephrine on the size of the TBGP and the distribution of cells therein, blood from each of eight subjects was labeled with $\mathrm{DFP}^{32}$, infused into the donor, and the TBGP and CGP were determined. Five days later the studies were repeated in the same subjects except that $0.5 \mathrm{mg}$ epinephrine was added to the labeled blood. The size of the TBGP was unaffected by the epinephrine (Table VI). However, the mean number of granulocytes in the CGP increased from $34.2 \times 10^{i}$ cells per $\mathrm{kg}$ to $50.5 \times 10^{-}$cells per $\mathrm{kg}$, a 48 per cent increase after administration of epinephrine.

TABLE $\mathrm{V}$

The size of the total blood granulocyte pool (TBGP) and circulating granulocyte pool (CGP) in 45 normal subjects

\begin{tabular}{lcc}
\hline & Mean \pm 1 SD & Range \\
\hline TBGP, cells $\times 10^{7} / \mathrm{kg}$ & $65.3 \pm 22.7$ & $36-117$ \\
CGP, cells $\times 10^{7} / \mathrm{kg}$ & $30.7 \pm 11.8$ & $15-54$ \\
TBGP-CGP, cells $\times 10^{7} / \mathrm{kg}$ & $34.6 \pm 15.6$ & $12-73$ \\
\hline
\end{tabular}


TABLE VI

\begin{tabular}{ccc}
\multicolumn{3}{c}{$\begin{array}{c}\text { Infuence of epinephrine and exercise on the } \\
\text { size of the TBGP and the CGP }\end{array}$} \\
\hline $\begin{array}{c}\text { Experimental } \\
\text { condition }\end{array}$ & TBGP & CGP \\
\hline & $\times 10^{7} \mathrm{G} / \mathrm{kg}$ & $\times 10^{7} \mathrm{G} / \mathrm{kg}$ \\
Control study* & 68.2 & 34.2 \\
After epinephrine & $(46-105)$ & $(17-54)$ \\
infusion* & 70.2 & 50.5 \\
& $(45-117)$ & $(31-70)$ \\
Control study $\dagger$ & 48.2 & 24.2 \\
& $(34-56)$ & $(16-41)$ \\
After exercise $\dagger$ & 47.1 & 38.6 \\
& $(36-53)$ & $(28-51)$ \\
\hline
\end{tabular}

* These values are the mean of studies on 8 subjects. $\dagger$ These values are the mean of studies on 3 subjects.

Similar studies were carried out in three adclitional subjects except that a 440 yard run at the completion of the infusion was used to mobilize granulocytes. Under the influence of exercise the TBGP size was also unchanged and again the cells were shifted into the CGP to increase its size by 60 per cent (Table VI).

\section{DISCUSSION}

The results of these studies indicate that labeled granulocytes are distributed in a pool of cells which is larger than that calculated from the blood volume and from the concentration of granulocytes in the circulating blood. This dilution accounts, in part at least, for the previous observation (1), confirmed herein, that only about 50 per cent of the infused cells can be accounted for in the CGP at the completion of an infusion. An average of 79 per cent of the infused, labeled cells was present in the CGP following the administration of epinephrine or after physical exercise.

Since only 71 to 88 per cent of the injected cells was found in the CGP following epinephrine infusion (Table I) and 54 to 100 per cent after vigorous exercise (Table II), it may be argued that a variable proportion of the labeled cells was damaged irreversibly or that this proportion of the label eluted rapidly from the granulocytes. However, in view of our previous studies relevant to damage and elution (3), it seems unlikely that either damage or elution accounts for this immediate loss of cells from the circulation. A more reasonable explanation for our inability to account for all of the injected cells in every experiment is that epinephrine and exercise did not mobilize all of the granulocytes in each subject. Indeed, this is suggested by the considerable variation of 0 to 278 per cent in neutrophilic response from person to person.

Equilibration between the granulocytes in the CGP and in the "noncirculating pool" was both rapid and complete. When the "noncirculating granulocytes" were mobilized into the CGP within minutes by either epinephrine or exercise (Table III), there was no change in the specific activity of the cells in the CGP. Therefore, these two pools may be considered as one pool kinetically, and the size of this pool (TBGP) may be determined by the use of the isotope dilution principle.

Measurement of the TBGP in normal subjects revealed that the mean TBGP is 2.1 times the size of the CGP. Although direct quantitative measurements of the size of the total blood granulocyte pool have not been made before, it was estimated that there are as many granulocytes in the marginal pool as in the circulating blood (7).

It is interesting that neither epinephrine nor exercise influenced the size of the TBGP, although both the drug and the physical exertion caused a shift of cells from the noncirculating pool to the CGP (Table VI). This type of alteration in the distribution of granulocytes within the blood has been the subject of speculation for many years and was called "pseudo-leukocytosis" by earlier investigators $(2,8)$. The present study provides the first evidence for the existence of this type of leukocytosis. One might speculate that the acute netutrophilia which is associated with epileptiform seizures (9) and paroxysmal tachycardia (10) may also be of this type.

Our studies do not provide evidence for the anatomical location of the noncirculating pool of granulocytes. However, as indicated in the introduction, there is abundant evidence that there is a continuous exchange of granulocytes between the free-flowing axial blood and the more slowly moving marginal stream (2). Vejlens (2) showed that when the velocity of blood flow is reduced, granulocytes tend to assume a marginal position, become adherent to the walls of small veins and are withdrawn from the axial stream. When the velocity of blood flow is increased, granulocytes enter the axial stream and are car- 
ried into the circulating blood. Since both exercise and epinephrine increase blood flow, it is reasonable to assume that these stimuli produce granulocytosis by mobilizing marginated cells. The work of Ambrus and Ambrus (11) and of Bierman and colleagues (12) suggests that the vascular system of the lungs is of particular significance in the margination of granulocytes. The importance of the vascular system of the splanchnic viscera (13) and extremities (14) has been demonstrated by the work of others. Apparently, the spleen plays a minor role in this regard, since granulocytosis induced by epinephrine is neither abolished nor diminished in splenectomized subjects (9).

\section{SUMMARY}

1. When granulocytes are labeled in vitro with radioactive diisopropylfluorophosphate and returned to the circulation of the donor, only about 50 per cent of the labeled granulocytes is present in the circulation at the completion of the infusion. It was postulated previously that the initial rapid egress of 50 per cent of the cells represented distribution of the injected granulocytes in a larger pool than that calculated from the blood volume and the venous granulocyte count. The experiments reported herein were designed to test the validity of this hypothesis. The following observations were made. a) An average of 78.8 per cent of the labeled granulocytes which were infused could be accounted for in the circulating blood when epinephrine was given with the infused cells. b) An average of 79 per cent of the labeled granulocytes was found in the circulation when the subjects exercised immediately following the completion of the infusion. c) Neither epinephrine nor exercise increased the size of the total distribution compartment (total blood granulocyte pool), although both the drug and physical exertion increased the size of the circulating granulocyte pool. d) Granulocytes damaged by storage could not be prevented from leaving the circulation by the administration of epinephrine. e) When granulocytes were mobilized into the circulation 3 hours after the infusion of labeled granulocytes, there was no change in the specific activity of the cells in the circulation.

2. These studies are interpreted as indicating that infused granulocytes are distributed in a total blood granulocyte pool (TBGP) made up of two compartments which are in rapid equilibrium with each other. These pools have been designated the circulating granulocyte pool (CGP) and the marginal granulocyte pool (MGP).

3. The size of these pools has been measured in 45 normal male subjects. The mean values \pm 1 $\mathrm{SD}$, expressed as number of cells $\times 10^{i}$ per $\mathrm{kg}$ of body weight, were as follows: TBGP, $65.3 \pm 22.7$; CGP, $30.7 \pm 11.8$; and MGP, 34.6 \pm 15.6 .

\section{ACKNOWLEDGMENTS}

The cooperation of Dr. William Knott and Warden John Turner of the Utah State Prison is very much appreciated. We are also grateful to those inmates of the Utah State Prison who volunteered for these studies. Mrs. Roseann Moore and Joyce Rose, and Misses Doris Kurth and Viktoria Wohlrab provided valuable technical assistance. We are grateful to Dr. M. H. Kuizenga, Upjohn Co., Kalamazoo, Mich., for the supplies of heparin sodium; to Dr. D. M. Monroe, Dow Corning, Corp., Los Angeles, Calif., for the silicone 4141; to Dr. G. M. Karus, Film Dept., E. I. DuPont de Nemours and Co., Wilmington, Del., for the Mylar; and to Dr. J. $\mathrm{H}$. Brewer, Hynson, Westcott and Dunning, Baltimore, Md., for the supply of crude cobra venom.

\section{REFERENCES}

1. Mauer, A. M., Athens, J. W., Ashenbrucker, H., Cartwright, G. E., and Wintrobe, M. M. Leukokinetic studies. II. A method for labeling granulocytes in vitro with radioactive diisopropylfluorophosphate $\left(\mathrm{DFP}^{32}\right)$. J. clin. Invest. 1960, 39, 1481.

2. Vejlens, G. The distribution of leukocytes in the vascular system. Acta path. microbiol. scand. 1938, suppl. 33.

3. Athens, J. W., Mauer, A. M., Ashenbrucker, H., Cartwright, G. E., and Wintrobe, M. M. Leukokinetic studies I. A method for labeling leukocytes with diisopropylfluorophosphate $\left(\mathrm{DFP}^{32}\right)$. Blood 1959, 14, 303.

4. Kurth, D., Athens, J. W., Cronkite, E. P., Cartwright, G. E., and Wintrobe, M. M. Unpublished data.

5. Baker, R. J., Kozoll, D. D., and Meyer, K. A. The use of surface area as a basis for establishing normal blood volume. Surg. Gynec. Obstet. 1957, 104, 183.

6. Peters, J. P., and Van Slyke, D. D. Quantitative Clinical Chemistry, 2nd ed. Baltimore, Williams and Wilkins, 1946, vol. 1, p. 29.

7. Craddock, C. G., Jr., Perry, S., and Lawrence, J. S. The dynamics of leukopenia and leukocytosis. Ann. intern. Med. 1960, 52, 281.

8. Goldscheider, A., and Jacob, P. Ueber die Variationen der Leukocytose. Z. klin. Med. 1894, 25, 373. 
9. Hortling, H. The influence of electric shock and adrenalin injections on the leukopoiesis and erythropoiesis. A contribution to the problem of a neurovegetative regulation of the hematopoiesis. Acta med. scand. 1947, suppl. 201.

10. Levine, S. A., and Golden, R. Some observations on paroxysmal rapid heart action with special reference to roentgen-ray measurements of the heart in and out of attacks. Arch. intern. Med. 1922, $29,836$.

11. Ambrus, J. L., and Ambrus, C. M. Regulation of the elimination of leukocytes in Brookhaven Symposia in Biology, no. 10, Homeostatic Mechanisms. Upton, N.Y., Brookhaven National Laboratory, 1958, p. 84.
12. Bierman, H. R., Kelly, K. H., Cordes, F. L., Byron, R. L., Jr., Polhemus, J. A., and Rappoport, S. The release of leukocytes and platelets from the pulmonary circulation by epinephrine. Blood 1952, 7, 683.

13. Villalobos, T. J., Adelson, E., Riley, P. A., Jr., and Crosby, W. H. A cause of the thrombocytopenia and leukopenia that occur in dogs during deep hypothermia. J. clin. Invest. 1958, 37, 1.

14. Bierman, H. R., Byron, R. L., Jr., Kelley, K. H., Cordes, F., White, L. P., and Littman, A. The influence of intra-arterial administration of histamine upon the circulating leukocytes of man. Blood 1953, 8, 315. 